\title{
Development ethnography and the limits of practice: a case study of life stories from Aceh, Indonesia
}

\author{
By Sonia Fèvre
}

\begin{abstract}
Drawing on life story interviews, this paper shows how individuals in Aceh, Indonesia, experienced social and economic changes after the Indian Ocean tsunami, while also continuing to grieve. It discusses the importance for the anthropologist of managing different identities, such as development worker and ethnographer, in a way that is ethical and appropriate, and considers how an engagement with development can enhance the resources and methodologies available to ethnographers to improve their practice of applied anthropology. Some of the ethical and practical challenges of working with communities who have experienced trauma are discussed, and insights and methodologies from the fields of oral history and counselling are proposed, which could help anthropologists to use more contextualised and adaptive approaches in their practice. In particular, issues of informant vulnerability and the importance of training and support are considered for ethnographers working with communities who have experienced trauma.
\end{abstract}

\section{Introduction}

Aceh's troubled history came to a climax on 26 December 2004 when the Indian Ocean tsunami hit coastlines across Asia and East Africa. The tsunami killed more than 228,000 people, with an estimated 167,540 deaths in Indonesia alone (Tsunami Global Lessons Learned Project 2009). In Aceh Province, where sea water reached 2 kilometres inland, the tsunami directly affected most residents in some capacity, and killed approximately one quarter of the population of the town of Meulaboh on the west coast of Sumatra (Usapdin 2005).

As a development worker living in Meulaboh, Aceh with communities who had experienced unprecedented tragedy, and working with people who brought strength and commitment to rebuilding the lives of their families and communities, I was inspired to find out more about how people had coped and how they saw their future. I was in a position of both observer and participant, ideal for conducting ethnography. But, given the traumatic nature of people's experiences and the embedded nature of my work in the NGO (nongovernmental organisation) community, the dual positioning brought with it its own set of ethical dilemmas. 
Based on my observations of social and institutional dynamics during the reconstruction efforts, I developed conflicting views about the development process itself, the methods and processes put in place to re-build physical and social communities, and the roles taken by different organisations and actors. Despite various programme evaluations and improved networking and communications between organisations after the emergency phase, it seemed like more could have been done to improve our reconstruction and development efforts through a stronger focus on the lived experiences of the participants of that reconstruction. What did the residents of Meulaboh think and feel about their lives now as compared to before the tsunami? What had changed and how could anthropological approaches help us understand such change? And how could ethnographic work with the direct beneficiaries of "development" inform our views of what is appropriate in anthropology?

One way to address these questions is by focusing on individuals and their experiences. The study of social change is a vast field populated by sociologists, anthropologists, theorists of organisational learning, development experts and others. NGOs themselves constantly try to understand how to contribute to positive social change and how to measure it. This paper looks at the types of change experienced by individuals during "development interventions" in Aceh. It considers how an engagement with development can enhance the resources and methodologies available to ethnographers to improve our practice of applied anthropology, and some of the ethical and practical challenges of working with communities who have experienced trauma.

I explain below the context of my ethnographic fieldwork in Aceh, followed by a discussion of life stories from residents of Meulaboh. I then consider some debates in development and anthropology and examine the role of the anthropologist in development. This is followed by a discussion of some of the institutional and ethical issues involved in practising anthropology with vulnerable communities who are coping with trauma.

\section{Ethnographic background}

My presence in Aceh as an observer of and participant in post-disaster reconstruction was initiated by my engagement in the work of an international development NGO carrying out community mobilisation activities. My organisation partnered with other agencies to build a network of community volunteers who could play a central role in mobilising residents. By 2008 most of the NGO activity in Meulaboh centred on long-term reconstruction projects for housing and infrastructure, with a small number of psychosocial and livelihoods projects still active from the emergency phase or recently introduced to help support long-term rehabilitation of the local population. Whilst most displaced persons had been provided with housing many still lived in temporary shelters awaiting new housing, which would be provided anytime between mid 2009 to late 2010 . 
The ethnographic research which informs this study was undertaken in the town of Meulaboh, Aceh province, Indonesia, between September 2007 and September 2008. The particular ethnographic data used to inform the focus on life histories was collected between April to September 2008 through one to one interviews with men and women who were residents of Meulaboh. My informants included people I met through my work as well as others I met through casual encounters. Some of them I chose because they seemed to have a story to tell, or a desire to talk about their experiences. I also tried to speak with both men and women who had a range of occupations, socioeconomic levels and housing conditions. Each informant was interviewed at least twice, usually with at least one formal recorded interview. All interviews and discussions took place in Indonesian, and recorded interviews ranged from one to three hours. The seven key informants were: Ibu Eli, market vendor, aged 45; Ibu Rosni, community volunteer, aged 35; Pak Andi, house security guard, aged 25; Pak Billy, NGO driver, aged 28; Ibu Meli, housewife and former UNDP waste collection site-worker, aged 33; Ibu Ipa, housewife and warung entrepreneur ${ }^{1}$, aged 37; Pak Yusuf, NGO officer and businessman, aged $33^{2}$. The poorest informant was lbu Meli who lived in fairly basic conditions in a half-cement half-wooden house in a village near Meulaboh, and the most well-off was Pak Yusuf who had a large modern house in the town centre and some disposable income.

\section{Life story narratives}

In order to exist in the social world with a comfortable sense of being a good, socially proper, and stable person, an individual needs to have a coherent, acceptable, and constantly revised life story (Linde 1993).

The notion that all individuals have a "life story" may seem obvious. The terms psychology, psychotherapy, counselling - though not necessarily fully understood - are familiar to many as representing relationships where people voluntarily discuss their lives and their past and in so doing create a coherent life story ${ }^{3}$ which helps explain their identity and development as a person. Thus just as communities and nations create stories which define their history and identity, it can be argued that individuals also generate coherent stories out of the events, emotions, observations and reflections which they have experienced throughout their life; and moreover, that they constantly attribute new meanings to events in light of new information.

1 A warung can be defined as "a type of small family owned business - often a casual, usually outdoor restaurant — in Indonesia", http://translation.sensagent.com/translate/warung/en/multilingual.html, accessed 05/10/09

2 Pseudonyms are used throughout this article to maintain the anonymity of informants. Ibu means Mrs and Pak means Mr.

3 A significant distinction is not made here between the terms 'life history' and 'life story' 
The linguist Charlotte Linde discusses the dual purpose for which anthropologists use life histories, which has important implications for the type of learning and skills which the ethnographer needs to utilise. Firstly, she describes the "portal approach" which uses life history as a means of learning "about some reality external to the story" (Linde 1993 informed by Peacock and Holland 1988), either as an account of history or ethnography, or "as a way to understand the subject's inner life, psychological history, and psychological structure, or to identify the psychological forces typical of the culture". Alternatively in the "process approach", the focus of study is the narrative itself, using linguistic and hermeneutic interpretations.

It may be that through the process of fieldwork an anthropologist's approach changes according to the information shared by her informants and a shifting focus of study. In considering life stories as data which reveal aspects of social change on the individual level, it is important for ethnographers to consider the psychological and philosophical implications of this assumption, and to be prepared to ask fundamental questions about the way people define their own lives and how and whether we can feasibly understand their lives in their own terms. My aim in this research was to understand in what ways the tsunami might have changed the way people saw their own lives after the tsunami.

Furthermore, in agreement with the "reactive approach" (Corsaro 1985 as applied by Mclntosh 2006:3), the discursive method employed in discussing informants' lives and histories was not a one-way process. For a start, I was actively engaged in community-related activities through my professional role and this meant that I was not only observing but was also sometimes consulting with, supporting or training some of my informants, or who knew my informants. In addition, within this specific cultural context, passive listening did not prove to elicit a strong desire to share information amongst my informants. Instead, it was usually easier to establish rapport by being involved in discussion, in some cases reflecting on their stories and relating them to my own experiences. This gave interviewees "the opportunity to discover who I was and why I wanted to learn from them" (Mclntosh 2006:1). Yet unlike the almost conspiratory relationship which Ruth Behar developed with her "comadre" informants in Mexico (Behar 1992), as a foreigner I was always to remain as "other" in the Acehnese setting. My conversations with women informants allowed me to develop closer relationships with them and for them to better understand who I was as a foreign woman, but I would remain an outsider.

Furthermore, the reluctance amongst interviewees to be in the limelight as storytellers of their own lives reflected a general reluctance to perceive their experiences in terms of a "life story". Indeed, on initiating my interviews, interviewees always expected me to ask specific questions and were uneasy with the idea of talking unprompted about sequences of life events. Depending on the rapport, spontaneity and self-confidence generated throughout the interviews, this either remained throughout or, as the informant relaxed, s/he became more comfortable about relating events and 
experiences without specific prompting. However, it was rare for my informants to enter into a long account of their life from beginning to end. Instead, they told separate accounts of specific events or stages in their life, and it was up to me as listener to piece these together. This struck me as wholly different from the type of life story accounts which other researchers have described from interviews in western cultures. For example, in analysing the narrative of his informant, an artist-craftsman in the USA, Elliot Mishler explains how the story achieved "the essential markers of the wellstructured narrative in the Western cultural tradition: a temporally ordered series of events [...], coherence at several levels [...], and the basic agentconflict-action structure [...]. Finally, the story has a "point" - it is not merely a chronicle of successive events" (Mishler 1992). My experience, on the other hand, echoes more closely that of the anthropologist Renato Rosaldo, who describes his difficulties in drawing out information about the "private self" of his Ilongot informants in the Philippines; instead, he focused on "narrative" as a means to extract contextual information about cultural mores and practices (Rosaldo 1976).

In my interviews with Ibu IPa, a housewife, mother and warung entrepreneur, she recounted discrete events in her life after the tsunami. When I wanted to find out more about her day to day activities now, I asked her about what her days were like and what she did, and it took a few tries for her to respond to these questions. This may have been partly due to a lack of self confidence, or a sense that what she did in her daily life was not significant enough to be worth telling. The conversation went a bit like this: today?

- Can you tell me about your life now, for example what did you do

— Work, just worked today

- All day?

- Yes, worked

- Oh I see. For example, did you cook today?

- Yes as soon as I woke up I did cooking and cleaning, then I took the children to school, then worked again: cleaning and cooking. 2 hours of rest then work again, shopping and cooking. When the family comes home then I cook. Then at night I go to bed and get up the next morning and start again. Pray in the morning, take the children to school, and so on.

Likewise, when encouraging Ibu Eli, a stall-owner in the Meulaboh outdoor market, to tell me about her childhood in the mountains, she was at a loss for what to say. It seemed as if childhood was such an obvious and insignificant episode that there was nothing special to say about it. She told me in a general way about going to school, helping her mother at home and playing with friends, but included little detail about what activities she did, what school was like or who she played with.

The notion of survival recurs amongst the stories of different informants, highlighting how many of them felt that they had been subject to forces beyond their control but had learned how to cope with both poverty and 
disaster. This is captured by Billy who had been a member of GAM, the Free Aceh Movement (Gerakan Aceh Merdeka) ${ }^{4}$ and who described to me the hardships and anxieties of surviving during the conflict, hiding in the mountains and rarely being able to see his family. He then went on to describe that even after the conflict and the tsunami he still struggled to survive in the new economic climate; he faced new and different challenges in supporting his wife and child. Likewise Ibu Meli, who was a housewife, mother, and had worked in the town's waste collection unit, described the hardships she faced in earning a sufficient income to support her family and take care of her children. Her husband had not completed primary school and his main source of income was through cutting and selling timber. She used to work in the new waste collection facility (a post-tsunami project) which allowed her to earn a decent wage, but now that she had a small baby she had to stay at home to look after him. Her days were busy and she often felt anxious about having to collect wood, earn money and also stay at home with her children.

On the one hand I encountered a general sense of powerlessness vis a vis the disaster: people's lives were changed forever due to this unpredictable and tragic event. On the other hand, experiences of dealing with the tsunami gave some people a certain sense of agency. Ibu Rosni, a community volunteer, had feelings of loss and grief for the family whom she lost; she also had strong feelings of guilt for not having been able to save her relatives; and a sense of thankfulness and confusion that she had been saved. In her worldview, to understand and come to terms with these events she attributed much of the causality and reason for this loss and life to God, yet there was also a recognition of the role she herself had played both in feeling that she had allowed a child to die, and in surviving herself.

In Ibu Ipa's accounts, there was a deep sense of loss and powerlessness immediately after the tsunami, waiting for the NGOs to provide food, shelter, and to organise long-term housing. However she also described how she and her family returned to their home location on the beach where they built a wooden house - which was still standing and served as their kitchen and storage room. They had had to wait about two years before they were provided with a permanent house, and the wooden structure had allowed them to live in their home environment and to start up a small business. They were also grateful to the "white" (buleh) friends they had made who had provided them with gifts such as a fridge and furniture; this had helped them in their cooking and restaurant business.

One of my informants talked about fundamental changes in his worldview which had occurred due to the tsunami and his subsequent activities. Pak

4 GAM had been a major separatist military and political force in Aceh since 1976, and some of its leaders eventually gained political power over the province after the ceasefire and Memorandum of Understanding with the Indonesian government in August 2005, and subsequent local elections in December 2006. For example former GAM member Irwandi Yusuf became the Governor of Aceh. 
Yusuf, an NGO officer, described in depth and over recurrent discussions how he had fundamentally changed as a person to become a better and more caring member of his community. Whereas before the tsunami he was just a businessman interested in making money, due to his network of friends and his innate skill at learning languages quickly, he was soon given positions of responsibility during the emergency operations and was now an officer in an NGO and a key member of his team. He cherished this new identity and the role that he could now play in helping other people grow, develop and learn new skills; just as he had done through his work and the support provided to him. He described this shift in self-identity as a learning and growing experience.

These views and feelings in no way undermine the real grief and continued sense of tragedy experienced by everyone I spoke to. There was never a sense that people were glad that the tsunami had happened. Ibu Rosni, for example, expressed her despair vis a vis the future, explaining that she had worked for years to build a small business (a small roadside stall) and had saved money and resources to do this, and yet because of the tsunami all this was lost. She could no longer plan ahead for the future, for who knew what would happen next?

Most informants demonstrated a resilience which impressed me not only as an anthropologist but as a development worker. I met many other people too who told me about how they had survived and rebuilt their lives, with everybody starting "on par" - they said it was as if God had given everybody the chance to be equal, and now there was peace and better economic opportunities in the province. This was due to a range of factors which were directly related to the tsunami, but also to the goodwill of people, groups and organisations to cooperate during a time of tragedy and crisis; people were willing to step away from the conflicts which had overshadowed their lives, particularly the ongoing conflict between GAM and the Indonesian government.

During an honest and moving discussion between some of the core volunteers who worked with my NGO, they all explained that their selfconfidence had improved drastically since the tsunami and that they had gained a freedom and access to opportunities which had not previously existed; they had the confidence to take initiatives and learn new skills without always needing the approval of their husbands. They attributed this to the various NGO projects which had been made available to them and described this as a fundamental and valuable improvement in their lives. This discussion is echoed in a study by Nowak and Caulfield who recount, from a post-tsunami study of women in Aceh, that "many of the women and men with whom we spoke claimed that the relationships between husbands and wives had improved since the tsunami, that "they understood each other better now". They said that they do not get angry at each other and are closer than they were prior to the tsunami... The women in Meulaboh said that their relationships with their husbands had become more intimate since the tsunami" (Nowak and Caulfield 2008: 39). 
Overall the most significant change event in all the respondents' lives was the tsunami. It seemed that in contrast to this one event, no other experience could compare in importance, whether it be getting married, having children or moving to a new part of the country. Whilst there was never a sense that the tsunami was "good", there was a general sense that people could not control God's will, and that many aspects of life had improved since before the tsunami.

\section{Development anthropology or anthropology of development}

Do we see ourselves as relatively detached observers or as persons committed to some program of action in relation to the people we study, and how is our study altered by our involvement? (Strathern and Stewart 2005:1)

Development anthropologist Maia Green highlights the potential stigma attributed by the "anthropology community" to the use of "instrumental" anthropological knowledge in the field of social development (Green 2003). She argues that all anthropology is somehow constrained by a political agenda, such that choosing to apply one's ethnographic lens to a development agenda carries no greater "stigma of subjectivity". Indeed, I would suggest that development anthropology (or anthropologists engaged in development activities) has an important part to play in contributing to the design and evaluation of humanitarian aid and that ethnographers should not limit themselves to a meta-analysis of the development framework itself, or the anthropology of development (Escobar 1997).

Ethnographic approaches have been adapted and transformed into shorthand methodologies for understanding cultural contexts and measuring the influence of development activities on social change, as discussed insightfully by Mosse in his article 'Social Research in Rural Development Projects'. His discussion highlights the role of action-oriented social research whose "outputs are... directed towards participants who are in a position to react to them whether 'beneficiaries' or programme managers" (Mosse 2001:164). Yet mainstream anthropology has sometimes sidelined these shorthand types of participatory research which are now so prevalent in community-based projects. Tools such as "participatory rural appraisal" (PRA) (Bartlett et al 2001), and the increasingly popular "Most Significant Change (MSC)" (Davies and Dart 1995) can provide anthropologists engaged in development with precisely the sort of instrumental knowledge which can help us learn more quickly about a wider target group and make connections and comparisons between groups, than a traditional long-term ethnographic approach would allow.

If anthropologists act within an institutional context which includes social change as one of its aims -such as in an NGO setting- it is also important for them to recognise the organisational measures available to them through which they can communicate their findings and exert influence. Mascarenhas-Keyes discusses the role that anthropologists increasingly play 
as researchers in organisations, and argues that "Such research is invariably policy- and practice-oriented, and, therefore, has to lead to recommendations for action" (Mascarenhas-Keyes 2001:205). She describes how the applied nature of her research for an organisation meant that the timing, pace and dissemination of her results were dictated by organisational priorities. In order to remain objective about the way one's research recommendations in an applied setting are received by different audiences, she recommends adopting a reflexive stance where one regards the "Self as Informant" and the "Self as Other", thus creating objectivity between her internal world of the organisation and the research process.

This attempt to remain objective about one's research results and the response of an audience is increasingly important for anthropologists to bear in mind. Whereas the relationship between ethnographic publications and their subjects may traditionally have been fairly distant, in an applied setting informants may well have a vested interest in knowing the results of a researcher's investigations; in fact these results and recommendations may have a direct impact on their lives in terms of decision-making about future aid or development interventions. The controversy (Balter 2009) over Jared Diamond's New Yorker article 'Vengeance is Ours' (Diamond 2008) about vengeance and warfare in the Papua New Guinea Highlands, for example, also highlights the possible repercussions including legal and financial claims, when an anthropological subject is actually empowered to contest the depiction made of him in a public medium, in what could be considered libel.

In my case, I had to be sensitive to the fact that I was working as "ethnographer" and as "development worker". While the distinction of these roles may have made sense to me personally, it was not clear to the people with whom I interacted locally. To them, my role in interviewing them was connected to my work for an NGO, and they may have hoped that I could influence the NGO community to further attend to their needs based on the information they shared with me. Despite explaining my situation to them that my interviews were not connected to my "official" work, I could not expect everyone to appreciate this. I was therefore intrinsically aware of the ethical issues relating to the types of expectations which I could be creating amongst informants. I was also aware that this could shape or influence the type of information they would be prepared to tell me, or the level of criticism they might be prepared to express. I was in a clear situation where despite, in an ideal scenario, wanting to be an objective observer, the implications of my role meant that my informants may have wanted me to be an advocate for them.

What was striking in the results of this fieldwork was informants' emphasis on economic and social change as a result of the tsunami and post-tsunami development projects. In particular, they described economic loss immediately after the tsunami, new economic opportunities now, and opportunities for developing new social roles, as alluded to earlier with regard to the community volunteers ${ }^{5}$. For example, although Ibu Ipa still worked

5 A World Bank study concludes that between 2004 (the tsunami year) to 2006 , the percentage of the population suffering from poverty had dropped by 2\% (Aceh Poverty Assessment 2008). 
hard, she explained that her days were a lot easier now that she did not have to wake up at 4am every morning to prepare cakes and snacks (kue), which had been her main source of income before the tsunami and before they had opened a 'warung'. And in spite of her grief, Ibu Rosni has embraced new opportunities provided to her by certain NGO activities. She became a volunteer for the barak (temporary housing community), and since then has collaborated with other volunteers to provide community activities and develop her skills as an educator. These life stories provided first-hand examples of how survivors felt more empowered over their own lives.

When speaking with Billy about the impacts of the tsunami and whether Aceh was still at risk of renewed conflict, he was very clear about the role of economics in the conflict. He explained: "The reason for the conflict was mainly economic, and secondly cultural. Economic because the Indonesian government took all the money away from Aceh. There was lots of industry here (cement, oil) but all the money left Aceh. Since the tsunami it's been different and people have a better quality of life. More people have a house and live better, so the economic conflict has largely gone away. I don't agree with the Partai Aceh who wants independence. Between fighting for independence and living safely like now, I prefer the situation now." The high value placed on peace and economic security was echoed by many other people with whom I spoke.

Informants' descriptions of the material gains which have been a consequence of the reconstruction process could be considered part of what NGOs sometimes refer to as "building back better". Although people had actively engaged in rebuilding their lives, there was little sense that they had helped direct the way the reconstruction process occurred; in this sense they were passive recipients of aid. Moreover, I was aware that my informants could not help but see me as a development worker, and indeed this role is what gave me legitimacy for residing and working in their community. As ethnographer, it was my responsibility to manage these identities and consider the implications of what I learned not only for my ethnography, but for my work in the community. In this sense I felt obligated to integrate my anthropological learning into my development activities, and to ensure that my questioning of the processes and evaluation of outcomes could inform my analysis of the development process itself, its strengths and failings.

\section{The limits of our practice}

... As I came to realize, training and experience as an autonomous, academic researcher does not sufficiently prepare one for working within a non-academic organization (Mascarenhas-Keyes 2001)

This quotation by Mascarenhas-Keyes highlights some of the key concerns about what becoming an anthropologist means and how one can apply one's research in the "real world". We can consider that by using a life story approach, the ethnographer is able to empathise first with the individual, and 
then to work outwards to the wider community. She must consider the social and psychological aspects of telling a story, and how events are represented in the telling of them. Marjorie Shostak (1981, 2000), for example, whose seminal accounts of Nisa's stories influenced future approaches to fieldwork, discusses how she was obliged not to judge the truthfulness of her informant, but to view Nisa's stories, however unrealistic they appeared, to be representations of Nisa's truth; this is referred to above as the portal approach (Linde ibid) to interpreting the story. One must consider, particularly after lifechanging events like the tsunami, how the act of telling one's story and the circumstances in which this occurs, may influence the way the narrator recalls and describes events. The types of memories people have, their willingness to talk about them, and the level of emotion they feel when talking about them are all factors which a researcher needs to consider when deciding what types of questions to ask informants and whether to push them to discuss painful events.

The role of anthropologist as advocate or change agent has been discussed at length in current debates ${ }^{6}$ and yet the role of anthropologist as therapist, or as clinical anthropologist (Van Willigen 2002) is sometimes not sufficiently recognised. Whilst anthropologists are not clinically trained to work as therapists, through their interactions and the techniques they use to elicit information from their informants and communities, they may well have an important and often unexpected impact. Conversely, Shostak admits that she was disappointed that Nisa did not express more satisfaction at having had the opportunity to tell her story, as if this telling should have acted as a therapeutic process for Nisa (2000). Along with many other ethical considerations in fieldwork, focusing on life stories demands the building of a sometimes intense, prolonged and trusting relationship with one's informants, possibly in interactions which the informant is not accustomed to in their usual cultural context. The fieldworker should be aware and continuously reflexive in developing these relationships.

In this study, it was obvious to me that requesting the involvement of an informant to take part in interviews with me was significant for them. Some people I approached amicably refused, either too shy or simply unwilling to have their accounts recorded. Most of those who accepted saw the relationship intrinsically as a personal relationship rather than as a professional exchange; this may have been different had I offered remuneration, but $I$ felt in this context remuneration would affect the trust required to hold honest conversations. In accepting to be interviewed, informants were accepting what they perceived as an offer of friendship, an interest on my part to get to know them better, to learn more about their lives. It was important for me as a guest in their culture and as someone involved in other projects in their communities, to be respectful of this expectation and to honour their subsequent expectations of me. I also felt I should be cautious in the way I asked questions and in the depth to which I tried to elicit information specifically related to the tsunami, its impacts on their family and their pain

6 See for example Ramos, Alcida Rita (2004), Hastrup, Kirsten and Elsass, Peter (1990). 
and grief: although people in Aceh readily referred to the observable facts related to the tsunami, such as the number of people who died or the things they lost, they were much less forthcoming in describing the emotions associated with these experiences.

Unlike a counsellor or therapist who may feel entitled to elicit stories and cocreate a narrative healing process with their client, such as in the use of narrative therapy techniques (Morgan 2000), I was not in a position to do this; this was not my intention, was not declared as such, and this was not the expectation of my informants. That said however, the very nature of entering into the intense social and personal experience of the interview implied, as explained above, that some degree of responsibility and expectation were imposed on me.

David Jones discusses the ethics of what is acceptable to ask in an interview in his article on oral history interviews conducted with people who have had distressing experiences. He argues that it is acceptable to discuss these events with people who have already talked about them before. He draws from an interview with a woman in her fifties who had been sexually abused as a child and had been involved in support groups for sexual abuse; he explains: "Something about the way she told me here, made me feel that it was safe territory" (1998). On the other hand, when interviewing another woman who mentioned in passing having been raped as a child, he did not feel it was ethically acceptable or emotionally sensitive to probe her about it. He explains that in this case she had developed a discourse to explain her experience, and his challenging her worldview would make the emotion raw and unmanageable:

"The reason I did not probe was that I felt that the incident had been rehearsed into a story. It was... encapsulated in a discourse, a discourse that I felt was better not to tamper with. My own thoughts here were of psychic damage and trauma... To Mrs Court, however, her forgetting was about a miracle, it was about her relationship to God. This was not something that I felt I understood. I did not feel able to probe any further, it seemed better not to disturb this story." (Jones 1998:51)

Jones' approach is insightful in highlighting the sensitivity the individual interviewer must exercise in order to judge what is appropriate and to question his/her own motivations for probing further. Why do we need to know? How will the knowledge we gain from an informant help the informant, the community, the discipline of anthropology, and can we justify the importance of this knowledge against the risk of reminding our informants of their pain, sadness or fear? It is worth noting that the American Anthropological Association's Code of Ethics states that obligations towards "people, species, and materials they study... can supersede the goal of seeking new knowledge, and can lead to decisions not to undertake or discontinue a research project..." (AAA 2009) and the Association of Social Anthropologists' Ethical Guidelines specifically highlight the issue of whether the search for knowledge should be pursued: 


\begin{abstract}
"[Anthropologists] should be aware that for research participants becoming the subject of anthropological description and interpretations can be a welcome experience, but it can also be a disturbing one.... the concern has resulted from participants' feelings of having suffered an intrusion into private and personal domains, or of having been wronged, (for example, by having been caused to acquire selfknowledge which they did not seek or want)" (ASA 1999).
\end{abstract}

Whilst some informants might seem unaffected by the process of talking, such as Nisa (as referenced above), there is of course an argument that providing informants with the opportunity to talk about traumatic events and distressing memories can in itself serve as a therapeutic process. For example, an interviewee in Wendy Rickard's study on the experience of recording oral history, said that listening back to her recorded interviews gave her rewarding insights which were different from therapy (Rickard 1998). Modern counselling and therapy developed out of a specific western historical and intellectual context, and may or may not be applicable elsewhere. Assuming that some tenets of therapy may be universal, such as the notion that talking about oneself and one's memories has inherent value, there are various conditions which allow for it to be therapeutic. One of these conditions is what is often referred to as "providing a safe space", meaning the interviewee feels comfortable. Jones warns of the risk of leaving interviewees feeling "overexposed" (Jones 1998:54), and this risk is enhanced if the interviewee is left feeling raw emotions and vulnerable, with no further opportunity to discuss them. Rickard's interviewee also states that her interviews were "more dangerous than therapy: which... is contained, and you have got somebody who's very responsible for you, because they're being paid to be..." (Rickard 1998:41).

I would therefore argue that the training and teaching of anthropology should at minimum encourage ethnographers to imagine and pre-empt these types of situations and expose them to principles and techniques from the fields of psychology, counselling and sociology, as well as from the anthropological literature, to manage expectations incurred through their role as participant observer in host communities and to be prepared to discuss trauma. Furthermore, it is worth considering three conditions laid out by the psychotherapist Carl Rogers to describe how a therapist can be an effective person-centred counsellor (Rogers 1951, 1957). Whilst recognising that the anthropologist is not a counsellor, these principles nevertheless highlight attitudes which the ethnographer could consider useful in her relationships with informants: a) the therapist should be congruent, genuine, transparent; she should relate to her client as herself rather than through a façade; $b$ ) she should have unconditional positive regard for her client and accept fully the client's feelings, values and behaviour without judgement, and c) she should experience empathetic understanding of the client, "To sense the client's private world as if it was your own".

Whereas this empathy should lead the therapist, through active listening, to 'reflect back' to the client through paraphrasing and summarising, this is 
where the role of anthropologist diverges. For example, during my fieldwork I was careful to use active listening during my interviews to show that I was listening and to engage my informants, but not with the aim of deepening their emotional state or breaking down their defence mechanisms for dealing with pain or trauma. The the anthropologist should remain cognisant of the benefits that developing a narrative to structure one's memories and situate meaning may have for her informants, and passively support her interviewees' own attempts to construct their own narratives, should they endeavour to do so, but without trying to play the role of therapist.

It is also important to acknowledge that the anthropologist herself may experience a range of difficult emotions when working with communities and individuals who have experienced trauma, and just as ethnographers may be prepared to experience "culture shock", they may also have to learn to cope with their own distress in hearing about other people's suffering. Jones recognises that the interviewer's feelings play a large part in determining how interviews proceed and how a research project may develop, and he proposes that oral historians should use coping strategies to avoid stress; these are: training, group (support) work and supervision (Jones ibid). I would suggest that these strategies could also be helpful for ethnographers.

The anthropologist can and must continually be honest and "act like herself" in her interactions to enhance trust and the validity of her experience. The teaching of anthropology can also encourage students to reflect and practise what this means in the field, by recognising that "by its very nature ethnography forces us into relationships with people: this in turn has an impact on how we behave... actions arise through obligations in another role... as a citizen and as a human being" (O'Neill 2001:229). Lessons from therapy and an understanding of the support and trust that informants may need in order to feel safe discussing trauma are essential parts of an ethnographer's practice.

\section{Conclusions}

This study has focused on the micro-level at which change can happen - that of the individual - to show that understanding individuals' experiences can enhance our understanding of change at the wider societal level. Applied anthropologists can help build this understanding in part through an appreciation of individuals' stories and the ways they choose to narrate them. The stories of survival discussed above reveal various common themes, including the positive effect of many NGOs in providing opportunity, education and empowerment; the central importance of economic well-being; and the sense of continued grief which individuals feel despite material improvements in their lives.

My fieldwork did not allow me to produce a neat, coherent "life story" for each of my informants. Instead, it highlighted to what extent the people I interviewed were not prepared to produce a life story, but rather wanted to tell me about stories from their lives. The assumption that people necessarily 
have a 'coherent, chronological life story' which can be told and re-told on whim may well be culturally-dependent, and did not seem applicable in the context of this work. People could speak about events, about causality and change, feelings and relationships, but these were complex aspects of a larger web and not neat units of one story. Rather than undermining the notion that life stories can be meaningful, this serves to reinforce the idea that learning about and understanding people's histories is complex and requires time. This highlights the difficulty of combining participatory evaluation approaches such as Most Significant Change (MSC), which uses people's stories of change, with the results-based management approaches which dominate the aid sector and which portray a linear model of how interventions lead to outputs, outcomes and impact. With her understanding of institutional processes, an anthropologist's ability to translate cultural concepts from development to real people and back may well be valuable in such exercises. Moreover, the success of ethnography in helping to inform development evaluation will depend largely on the trust and rapport established between interviewer and informants, the motives and expectations they may have in sharing their stories, and a range of cultural factors which may place differential values on the importance or appropriateness of reflecting upon and analysing one's life experiences.

The ethnographer's circumstances will always influence the relationships she develops with her informants, including features such as age, gender, ethnic background, personality, as well her role and perceived entitlement to be in the community and to ask the questions she chooses to ask. With an increasing tendency for organisations to employ anthropologists to study their own organisational processes, this dual identity of employee (with contractual obligations) and researcher (with ethical obligations to those whom she studies) may become increasingly problematic. The subjectivity inherent to qualitative data collection is particularly significant when collecting life story data through interviews, where the information gleaned is dependent on the type of relationship which exists between researcher and informant. It is partly for this reason that I would urge an ethnographer in such a setting to complement her study with a variety of other approaches, such as general participant observation, informal discussions, in addition to more focused methods to elicit information such as PRA and MSC methodologies. In this particular study my role as development worker would have influenced the perceptions of my informants whilst also legitimising my presence in their community. My status as a fairly young, foreign female incited curiosity and sometimes goodwill. And my experience living and working with community members allowed me to assess and question the historical validity of the information I collected, based on conversations and formal evaluations which I conducted in parallel to the interviews carried out for this project.

In the context of post-tsunami Aceh, some of the resounding individual reflections I encountered included people's attempts to come to terms with uncertainty and the inability to predict the future, as well as a resilience against hardship and a willingness to rebuild their lives. Yet, despite sensing and believing that informants spoke openly, there was an inherent dynamic to my fieldwork relationships which meant that I was constantly aware of my 
position as foreigner and development worker, as well as interviewer and ethnographer. I also felt accountable for using this knowledge instrumentally in my practice of development.

Choosing to work with a selection of individuals' life stories as my main ethnographic method allowed me to focus on the subjectivities of the tellers and to thereby gain insights into the types of social change which had occurred since the tsunami and what this meant to individuals. I would also argue that the teaching of anthropology can and should be enhanced through a greater acknowledgement of the range and variety of tools available for collecting and examining social data, such as those used in participatory development.

Moreover, anthropological thinking about ethnographic methods should refer more self-consciously to sister disciplines and applied subjects such as psychology, counselling and community development, where ethical considerations are explicit to their practice. The ethnographer's presence and interventions may have real and unexpected consequences; not only in terms of how the anthropologist's involvement with her host culture may affect it, but in terms of her very real and direct impact on the individuals with whom she interacts. As anthropologists increasingly work in disaster-affected areas and with vulnerable populations, it is paramount that we acknowledge and become responsible for the relationships and people with whom we engage, and sensitive to how our interactions may play with their private feelings of stress, grief, trauma and hope. Various strategies and approaches are discussed above which can help us use our sensitivities and common sense to decide what types of questions and probing are appropriate when working with people who have experienced trauma. Providing a safe space, recognising the limits of our role, and allowing the informant to decide how much they want to tell, are all key factors which should guide the way we conduct interviews and respect the personal boundaries of the people with whom we work. In an applied setting, there is no naïve participant observation. Rather ethnography plays out as a form of anthropological practice, much like the work of a counsellor or development worker.

\section{About the author}

Sonia Fèvre is an international development professional currently working in South and Southeast Asia. She has worked for diverse NGOs on issues related to community development, environmental regeneration and ecosystem approaches to health. Her research interests include participatory research, approaches to monitoring and evaluation, and organisational development. She holds an MA in Social Anthropology (University of Cambridge) and an MSc in Environmental Technology (Imperial College London). She can be contacted at sfevre@cantab.net

\section{Acknowledgements}


I would like to express my thanks to the informants of this study for generously spending time and effort in discussing their lives and experiences. Thanks also to C-SAP, University of Birmingham, for kindly providing the Teaching and Learning in Anthropology grant which financed this work.

\section{References}

Balter, M. 2009. 'Vengeance' Bites Back at Jared Diamond' in Science 324(5929): $872-874$.

Bartlett, S., Hill, J. and Arnold, C. 2001. Conversations with Families to Prepare for Early Childhood Programming: Participatory Research Handbook. Kathmandu: Save the Children Norway, US and UK with UNICEF ROSA.

Behar, R. 1992. A Life Story to Take across the Border: Notes on an Exchange. In Storied Lives: The Cultural Politics of Self-Understanding (eds.) Rosenwald, G.C. and Ochberg, R.L. New Haven and London: Yale University Press.

Corsaro, W.A. and Molinari, L. 2000. Entering and observing in children's worlds: a reflection on a longitudal ethnography of early education in Italy. In Research with Children: Perspectives and Practices (eds.) Christensen, P and James, A. London: Falmer Press.

Diamond, J. 2008. 'Vengeance is Ours. What can tribal societies tell us about our need to get even?' in The New Yorker, 21 April.

Davies, R. and Dart, J. 2005. The 'Most Significant Change' (MSC)

Technique: A Guide to Its Use (available online at:

http://www.mande.co.uk/docs/MSCGuide.pdf ).

Escobar, A. 1997. 'Anthropology and Development' in International Social Science Journal 154: 497-516.

Green, M. 2003. 'International Development, Social Analysis....and Anthropology? Applying Anthropology in and to Development' in Applications of Anthropology Workshop, Loughborough.

Hastrup, K. and Elsass, P. 1990. 'Anthropological Advocacy: A Contradiction in Terms?' in Current Anthropology 31(3). The University of Chicago Press.

Jones, D. 1998. 'Distressing Histories and Unhappy Interviewing' in The Journal of the Oral History Society 26(2):49-56.

Linde, C. 1993. Life Stories: The Creation of Coherence. New York, Oxford: Oxford University Press.

Mascarenhas-Keyes, S. 2001. Understanding the Working Environment: Notes Towards a Rapid Organizational Analysis. In Inside Organizations. 
Anthropologists at Work (ed). Gellner, D. and Hirsch, E. Oxford, New York: Berg.

Mclntosh, J. 2006. 'How dancing, singing and playing shape the ethnographer: research with children in a Balinese dance studio' in Anthropology Matters 8(2).

Mishler, E.G. 1992. Work, Identity and Narrative: An Artist-Craftsman's Story. In Storied Lives: The Cultural Politics of Self-Understanding (eds.)

Rosenwald, G.C. and Ochberg, R.L. New Haven and London: Yale University Press.

Morgan, A. 2000. What is Narrative Therapy?: An Easy to Read Introduction. Dulwich Centre Publications.

Mosse, D. 2001. Social Research in Rural Development Projects. In Inside Organizations: Anthropologists at Work (ed.) Gellner, D. and Hirsch, E. Oxford, New York: Berg.

Nowak, B.S. and Caulfield, T. 2008. 'Women and Livelihoods in Post-Tsunami India and Aceh' in Asia Research Institute Working Paper Series 104. Asia Research Institute, National University of Singapore.

O'Neill, M. 2001. Participation or Observation? Some Practical and Ethical Dilemmas. In Inside Organizations: Anthropologists at Work (ed.) Gellner, D. and Hirsch, E. Oxford, New York: Berg.

Peacock, J. and Holland, D. 1988. 'The Narrated Self: Life Stories and Self Construction'. Symposium on Self Narrative, American Anthropological Association Meeting. Phoenix, Arizona.

Ramos, A.R. 2004. Advocacy Rhymes with Anthropology. In Expert Knowledge. First World Peoples, Consultancy, and Anthropology (eds.) Morris, B and Bastin, R. Berghahn Books.

Rickard, Wendy (1998) 'Oral history - 'More dangerous than therapy?' Interviewees' reflections on recording traumatic or taboo issues' in The Journal of the Oral History Society, 26(2):34-48.

Rogers, C. 1951. Client-Centered Therapy. Boston: Houghton Mifflin.

Rogers, C. 1957. 'The necessary and sufficient conditions of therapeutic personality change' in Journal of consulting and clinical psychology 21:95103. Washington, DC.

Rosaldo, R. 1976. The Story of Tukbaw: 'They Listen as He Orates. In The Biographical Process: Studies in the History and Psychology of Religion (ed.) Reynolds, F. and Capps, D. Mouton. 
Shostak, M. 1981. Nisa, the life and words of a !Kung woman. Cambridge, MA: Harvard University Press.

Shostak, M. 2000. Return to Nisa. Cambridge, MA: Harvard University Press.

Strathern, A. and Stewart, P.J. 2005 Introduction. Anthropology and Consultancy - Ethnographic Dilemmas and Opportunities. In Anthropology and Consultancy: Issues and Debates. Stewart, P.J. and Strathern, A. (ed.) New York, Oxford: Berghahn Books.

Usapdin, T.P. 2005. Humanitarian 'soldier' restores dignity to Meulaboh's dead. IFRC (available online

http://www.ifrc.org/docs/News/05/05051202/index.asp (05/07/09).

Van Willigen, J. 2002. Applied Anthropology: An Introduction. Wesptort: Bergin and Garvey.

--- 2009. Code of Ethics of the American Anthropological Association (available online: http://www.aaanet.org/issues/policy-advocacy/Code-ofEthics.cfm\# ).

--- 1999. Ethical Guidelines for Good Research Practice. The Association of Social Anthropologists of the UK and the Commonwealth (available online: http://www.theasa.org/ethics/guidelines.htm ).

--- 2008. Aceh Poverty Assessment: The Impact of the Conflict, the Tsunami and Reconstruction on Poverty in Aceh. The World Bank.

--- 2009 The Tsunami Legacy. Innovation, Breakthroughs and Change. The Tsunami Global Lessons Learned Project. 